\title{
DISTRIBUTION AND DESCRIPTIVE CHARACTERISTICS OF THE TWO GIANT PILL MILLIPEDES OF THE GENUS Sphaerobelum Verhoeff, 1924 (Diplopoda, Sphaerotheriida, Zephroniidae) IN VIETNAM
}

\author{
Nguyen Duc Anh", ${ }^{1, *}$ Petra Sierwald ${ }^{2}$ \\ ${ }^{1}$ Institute of Ecology and Biological Resources, VAST, Vietnam \\ ${ }^{2}$ Field Museum of Natural History, 1400 S LakeShore Drive, Chicago, IL 60605, USA \\ Received 27 February, accepted 12 February 2019
}

\begin{abstract}
Two giant pill millipedes, Sphaerobelum clavigerum Verhoeff, 1924 and Sphaerobelum hirsutum Verhoeff, 1924, were described from unindicated localities in northern Vietnam. The paper presents the recorded localities, descriptions and colour illustrations of those giant pill millipedes. S. clavigerum Verhoeff is recorded from Cuc Phuong National Park (Ninh Binh Province), and distinguished from its congeners by body being shiny, glabrous, anterior telopods 3 -segmented, process of $2^{\text {nd }}$ podonomere of posterior telopods slender, not apically strongly swollen. In contrast, S. hirsutum Verhoeff is found in Tam Dao National Park and Me Linh Biodiversity Station (both in Vinh Phuc Province), and recognized by body being densely hairy, process of $2^{\text {nd }}$ podonomere of posterior telopods apically strongly swollen, spherical, wider than basis of $3^{\text {rd }}$ podomere. In addition, a key to genera of giant pill millipedes is also provided for the Vietnam fauna.
\end{abstract}

Keywords: Millipede, Sphaerotherida, Zephroniida, Sphaerobelum, distribution, Vietnam.

Citation: Nguyen Duc Anh, Sierwald, P., 2019. Distribution and descriptive characteristics of the two giant pill millipedes of the genus Sphaerobelum Verhoeff, 1924 (Diplopoda, Sphaerotheriida, Zephroniidae) in Vietnam. Tap chi Sinh hoc, 41(1): 9-17. https://doi.org/10.15625/0866-7160/v41n1.11400.

*Corresponding author email: ducanh@iebr.ac.vn

(C2019 Vietnam Academy of Science and Technology (VAST) 


\title{
PHÂN BỐ VÀ ĐẠC ĐIỂM MÔ TẢ HAI LOÀI SÂU ĐÁ LỚN GIỐNG Sphaerobelum Verhoeff, 1924 (Diplopoda, Sphaerotheriida, Zephroniidae) Ở VIẸT NAM
}

\author{
Nguyễn Đức Anh ${ }^{1, *}$, Petra Sierwald ${ }^{2}$ \\ ${ }^{1}$ Viện Sinh thái và Tài nguyên Sinh vật, Viện Hàn lâm Khoa học và Công nghệ Việt Nam, Việt Nam \\ ${ }^{2}$ Bảo tàng Lịch sử tự nhiên, $1400 \mathrm{~S}$ LakeShore Drive, Chicago, IL 60605, USA
}

Ngày nhận bài 27-2-2018, ngày chấp nhận 12-2-2019

\section{TÓM TẮT}

Hai loài sâu đá lớn, Sphaerobelum clavigerum Verhoeff, 1924 và Sphaerobelum clavigerum Verhoeff, 1924 được mô tả trên các mẫu vật nhưng không chỉ rõ các địa điểm thu thập ở miền Bắc Việt Nam. Cho đến nay, chưa có thông tin chi tiết về hai loài sâu đá lớn này. Bài báo này cung cấp các địa điểm phân bố cụ thể, đặc điểm và hình ảnh mô tả của hai loài sâu đá lớn. Loài $S$. clavigerum được ghi nhận ở Vườn Quốc gia Cúc Phương, tỉnh Ninh Bình, được nhận dạng với các đặc điểm: bề mặt cơ thể sáng bóng, trơn nhẵn; chân giao phối trước có 3 đốt, phần phụ của đốt thứ hai chân giao phối sau dạng hình trụ, thon và hơi phình to về phía đầu. Trong khi đó, loài S. hirsutum được tìm thấy ở Vườn Quốc gia Tam Đảo và khu vực Trạm Đa dạng Sinh học Mê Linh, tỉnh Vĩnh Phúc và được phân biệt bằng các đặc điểm: Bề mặt cơ thể có nhiều lông tơ nhỏ, phần phụ của đốt thứ hai chân giao phối sau phình to về phía đỉnh, có chiều rộng lớn hơn cả chiều rộng ở gốc đốt thứ 3 . Bên cạnh đó, bài báo cũng đưa ra khóa định loại đến các giống sâu đá lớn ở Việt Nam.

Từ khóa: Millipede, Sphaerotherida, Zephroniidae, chân kép, sâu đá, phân bố, Việt Nam.

"Địa chỉ liên hệ email: ducanh@iebr.ac.vn

\section{MỞ ĐÀ̀}

Nhóm sâu đá lớn là tên gọi khác của động vật chân kép thuộc bộ Sphaerotheriida, lớp chân kép (Diplopoda). Nhóm sâu đá lớn phân bố rộng trên thế giới (Minelli, 2015; Wesener, 2016). Chúng có kích thước khá lớn khi so sánh với các nhóm chân kép khác, và có khả năng cuộn tròn cơ thể thành những quả bóng. Đây là một trong những phương thức tự vệ của nhóm động vật này trước các loài thiên địch (Hopkin \& Read, 1992; Minelli, 2015).

Cho đến nay, bộ Sphaerotheriida có khoảng 351 loài đã được mô tả, và phân bố ở Nam Phi, Madagasca, toàn vùng Đông phương và kéo dài xuống New Zealand và Australia (Minelli, 2015; Wesener, 2016). Bộ
Sâu đá lớn được phân chia thành 4 họ: Sphaerotheriidae phân bố ở Nam Phi; Procyliosomatidae phân bố ở Australia and New Zealand; Arthrosphaeridae chỉ phân bố ở Nam Ân Độ và Madagascar; Zephroniidae phân bố toàn khu vực Đông Nam Á với 140 loài thuộc 14 giống được ghi nhận (Wesener et al., 2010; Minelli, 2015; Wesener, 2016).

Ở Việt Nam, đã ghi nhận được 9 loài thuộc 4 giống, 1 họ (Zephroniidae) (Enghoff et al., 2004). Trong số 9 loài, Verhoeff (1924) đã mô tả 4 loài trên cơ sở các mẫu vật thu từ các địa điểm không xác định ở miền Bắc Việt Nam, đó là bốn loài sau:

Prionobelum durum Verhoeff, 1924: Tonkin (= Bắc bộ Việt Nam); 
Sphaerobelum clavigerum Verhoeff, 1924: Tonkin (= Bắc bộ Việt Nam);

Sphaerobelum hirsutum Verhoeff, 1924: Tonkin (= Bắc bộ Việt Nam);

Sphaeropoeus maculatus (Verhoeff, 1924): núi Mẫu Sơn, Lạng Sơn.

Ngoài ra, địa điểm của mẫu chuẩn hiện nay cũng chưa được xác định rõ ràng. Verhoeff (1924) chỉ cồng bố địa điểm thu mẫu chuẩn như Tonkin (= Bắc Bộ Việt Nam) cho các loài được mô tả. Điều này gây khó khăn cho việc nghiên cứu, thu mẫu và xác định sự phân bố của loài. Thêm vào đó, Verhoeff (1924) chỉ đưa hình vẽ mô tả về chân giao phối của loài $S$. clavigerum, nhưng hình mờ và không rõ. Vì vậy, bài báo của chúng tôi lần đầu tiên đưa ra địa điểm phân bố cụ thể, mô tả và hình ảnh của hai loài sâu đá lớn Sphaerobelum clavigerum Verhoeff và Sphaerobelum hirsutum Verhoeff. Ngoài ra, khóa định loại đến giống của họ Zephroniidae ở Việt Nam cũng được thiết lập nhằm hỗ trợ việc nghiên cứu nhóm động vật này.

\section{VÂT LIỆ VÀ PHƯƠNG PHÁP NGHIÊN CỬU}

Mẫu vật được thu thập trong chuyến khảo sát thực địa của Viện Sinh thái và Tài nguyên Sinh vật, Viện Hàn lâm Khoa học và Công nghệ Việt Nam và Bảo tàng Lịch sử tự nhiên Chicago (Field Museum of Natural History), Hoa Kỳ. Mẫu vật được thu thập bằng tay hoặc các rây đất, bảo quản trong cồn $80 \%$. Hình thái ngoài, chân giao phối được quan sát dưới kính lúp soi nổi Leica MZ125. Các đặc điểm hình thái được so sánh với mô tả gốc của Verhoeff (1924). Ảnh được chụp bằng máy ảnh Nikon 5100 với hệ thống ống kính chuyên dụng. Các thuật ngữ được sử dụng theo Wongthamwanich et al. (2012) và Wesener (2016). Các tài liệu Wongthamwanich et al. (2012), Weserner (2016), Verhoeff (1924), Attems (1953) được sử dụng để thiết lập khóa định loại đến giống của họ Zephroniidae ở Việt Nam.

Mẫu vật được lưu giữ tại Viện Sinh thái và Tài nguyên Sinh vật, Viện Hàn lâm Khoa học và Công nghệ Việt Nam, và Bảo tàng Lịch sử tự nhiên (Field Museum of Natural History), Chicago (USA).

\section{KẾT QUẢ VÀ THẢO LUẬN}

\section{Giống Sphaerobelum Verhoeff, 1924}

Loài chuẩn: Sphaerobelum clavigerum Verhoeff, 1924.

Đặc điểm chẩn loại: Cơ thể có 13 đốt, chiều dài khoảng từ $20-45 \mathrm{~mm}$. Đốt bàn chân chỉ có 1 gai đơn. Chân giao phối trước có 3-4 đốt; đốt thứ hai có phần phụ đơn giản, và hơi uốn cong về phía sau. Chân giao phối sau có 4 đốt; phần phụ đốt thứ hai lớn dần về phía đỉnh (Minelli, 2016).

Nhận xét: Giống Sphaerobelum có 5 loài, bao gồm: S. bicorne Attems, 1938 ghi nhận ở Vườn Quốc gia Bà Nà (Việt Nam), $S$. separatum Attems, 1953 ghi nhận ở núi Fanxifan, Vườn Quốc gia Hoàng Liên (Việt Nam), S. clavigerum Verhoeff, 1924, S. hirsutum Verhoeff, 1924, cả hai loài đều ghi nhận ở miền Bắc Việt Nam (không rõ địa điểm cụ thể), S. truncatum Wongthamwanich, 2012 ghi nhận ở tỉnh Nan (Thailand).

Sphaerobelum clavigerum Verhoeff, 1924 (hình 1A, 2-3)

Mẫu vật nghiên cứu: 2 cá thể đực, 1 cá thể cái (FMNH-SVE-170), Việt Nam, Ninh Bình, Vườn Quốc gia Cúc Phương, $20^{\circ} 19^{\prime} 0,18^{\prime \prime} \mathrm{N} \quad 105^{\circ} 36^{\prime} 29,23^{\prime \prime} \mathrm{E}, 22 / 09 / 2016$, coll. Petra Sierwald et al.

\section{Mô tả:}

Có 13 đốt. Ở trạng thái cuốn tròn, chiều dài khoảng $22 \mathrm{~mm}$ (cá thể đực), $28 \mathrm{~mm}$ (cá thể cái), chiều rộng khoảng $18 \mathrm{~mm}$ (cá thể đực) and $22 \mathrm{~mm}$ (cá thể cái). Cơ thể có mầu nâu hat dẻ pha lẫn mầu xanh ở một số vùng trên tấm lưng. Chân màu vàng nâu, ngoại trừ đốt ống và đốt bàn chân có màu xanh. Râu có mầu đen, đỉnh râu màu vàng. Không có các tơ hoặc lông nhỏ dày đặc trên các tấm lưng, tấm khiên ngực, tấm cổ và đầu.

Đầu có dạng hình thang, hơi lõm ở mép trên (hình $2 \mathrm{~A}-2 \mathrm{D}$ ); tơ nhiều ở vùng gần tấm hàm môi, và thưa dần về phía sau. Khu vực mắt tròn, có khoảng 60-64 mắt đơn (hình 2E). Cơ quan Tomosvary nằm giữa mắt và râu, nhưng tách biệt rõ rang (hình $2 \mathrm{E}$ ). Râu rất ngắn, đặc biệt các đốt $1-5$, đốt râu 6 rất lớn, 
dạng hình chùy, hoặc hình nắm tay (hình $2 \mathrm{~A}-$ 2D); phần đỉnh râu có $50-53$ nhú cảm giác

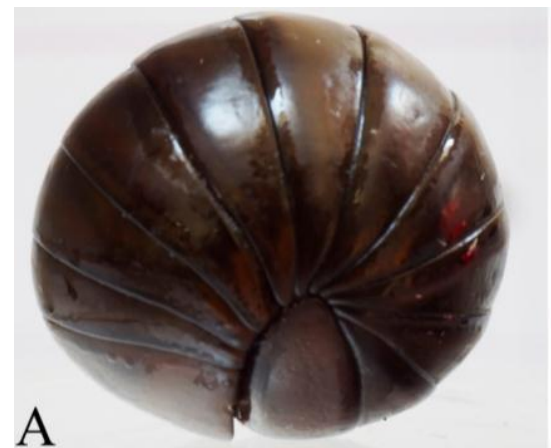

(hình 2F).

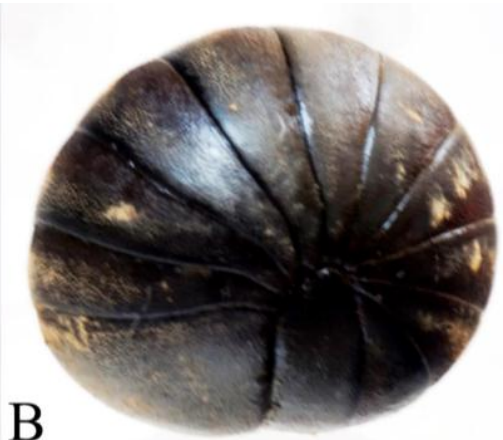

Hình 1. Sphaerobelum clavigerum Verhoeff, 1924, mẫu thu ở Cúc Phương (A); Sphaerobelum hirsutum Verhoeff, 1924, mẫu thu ở Tam Đảo (B)

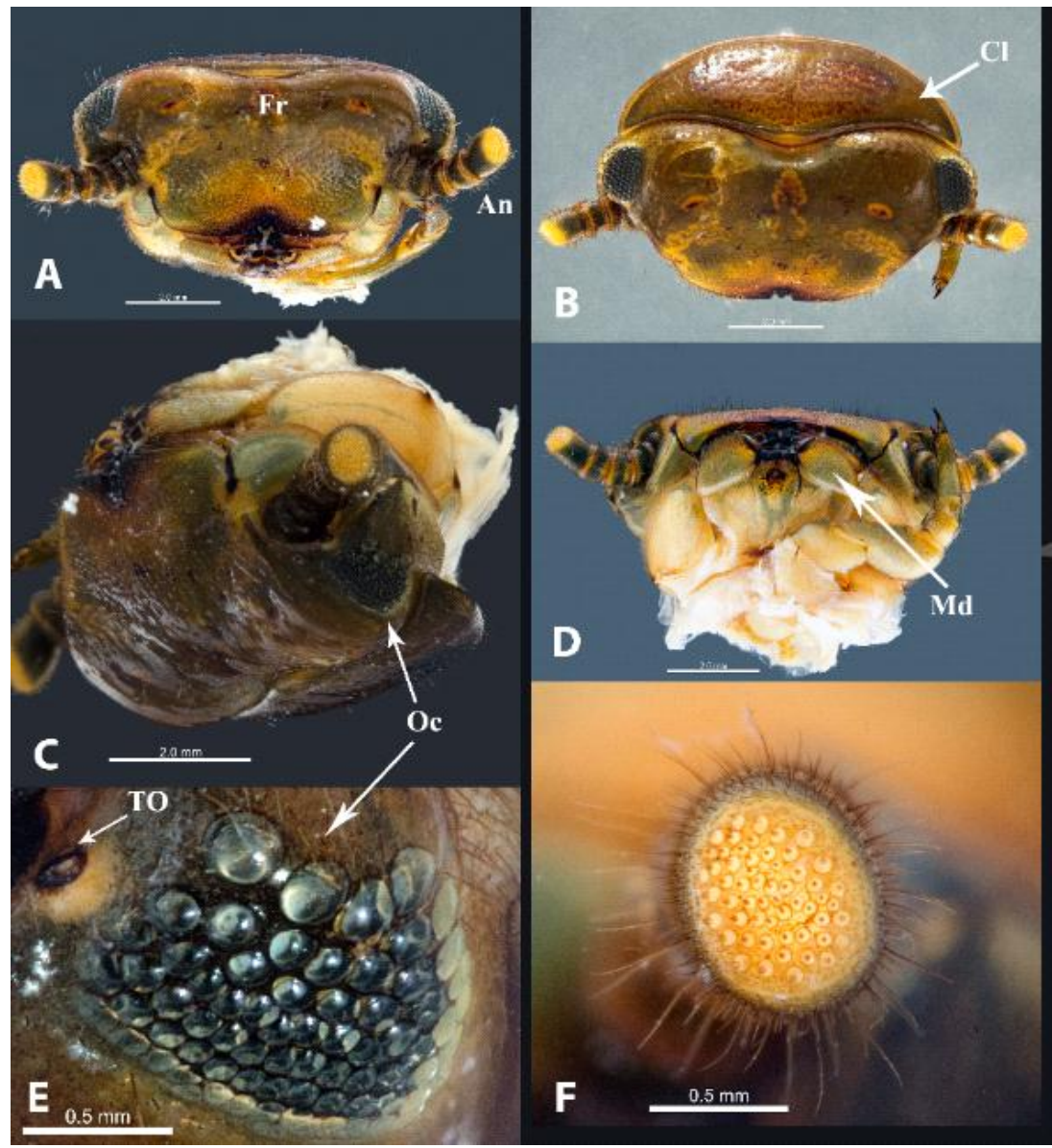

Hình 2. Sphaerobelum clavigerum Verhoeff, 1924, mẫu thu ở Cúc Phương: Phần đầu, nhìn từ đằng trước $(\mathrm{A})$, nhìn từ phía trên $(\mathrm{B})$, nhìn từ bên $(\mathrm{C})$, nhìn từ phía dưới $(\mathrm{D})$; Vùng mắt $(\mathrm{E})$; Nhú cảm giác của râu $(\mathrm{F}) ; \mathrm{Fr}=\mathrm{Trán} ; \mathrm{Cl}=$ Tấm cổ; $\mathrm{An}=\mathrm{Râu} ; \mathrm{Md}=$ Tấm hàm; $\mathrm{Oc}=$ Mắt đơn; $\mathrm{TO}=$ Cơ quan Tomoswary 


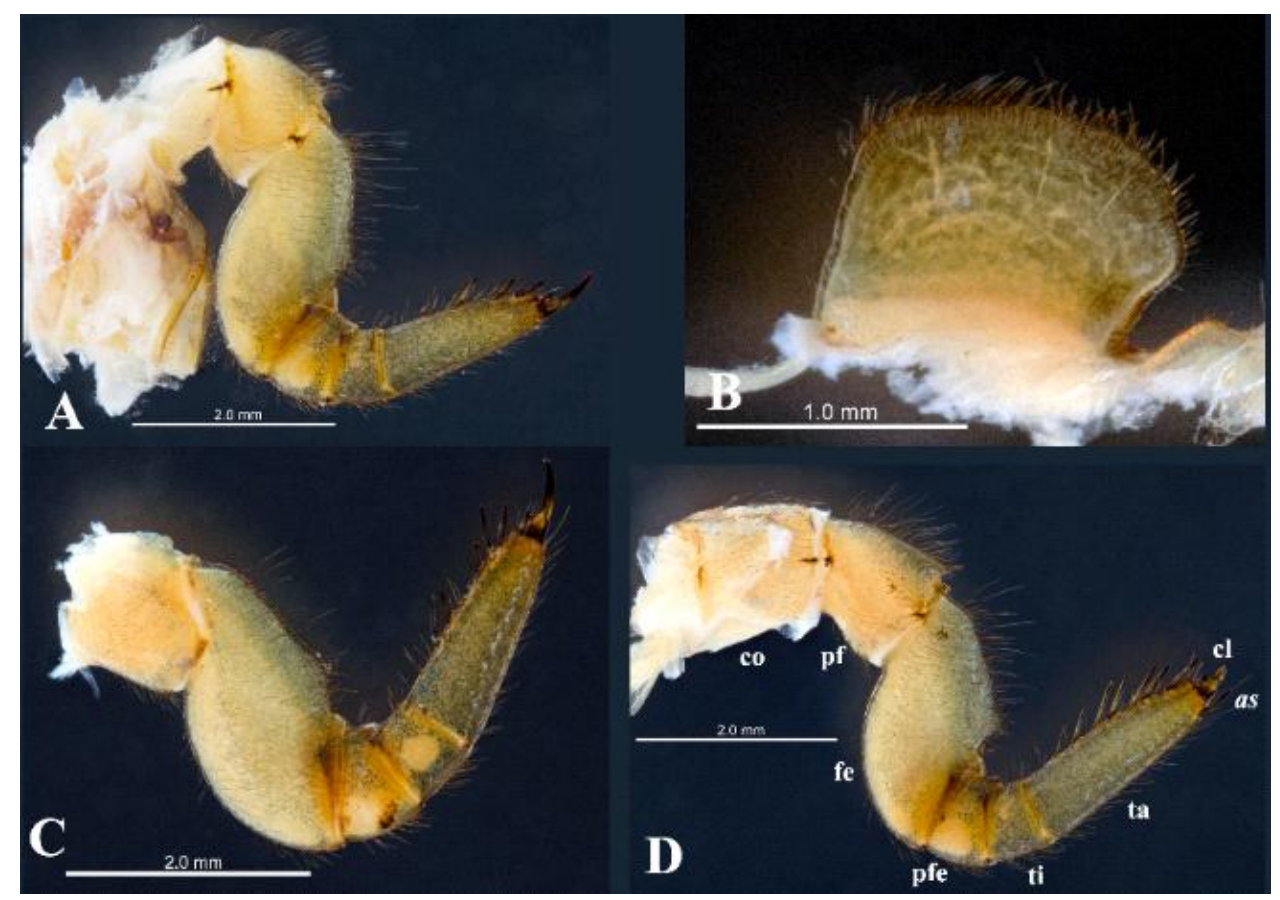

Hình 3. Sphaerobelum clavigerum Verhoeff, 1924, mẫu thu ở Cúc Phương: Chân thứ nhất (A);

Thùy stigma của chân thứ nhất (B); Chân thứ hai (C); Chân thứ ba (D); co = đốt khớp háng; $\mathrm{pf}=$ đốt trước đùi; $\mathrm{fe}=$ đốt đùi; $\mathrm{pfe}=$ đốt sau đùi; $\mathrm{ti}=$ đốt ống; $\mathrm{ta}=$ đốt bàn; $\mathrm{cl}=$ vuốt; as = gai ở đỉnh

Tấm cổ hình bán nguyệt, màu xanh đen, có tơ thưa thớt ở khu vực mép trước và mép sau; mép trước hơi cong về phía trước; gò̀ trước và sau rất rõ ràng.

Tấm khiên ngực trơn nhẵn ở phần giữa, và có tơ rải rác ở vùng mép trước và mép sau. Gờ sau tiêu giảm hoặc không rõ ràng; gờ trước và gờ bên rất rõ, lớn. Rãnh phân chia gờ trước và tấm khiên ngực sâu, dễ quan sát.

Tấm lưng trơn nhẵn, sáng bóng. Vùng gần mép sau có mầu sẫm hơn so với mầu nâu vàng của khu vực còn lại. Không có rãnh hoặc gờ phân chia trên tấm lưng.

Tấm hậu môn trơn, nhẵn, sáng bóng và có một gờ ngang ở ngay chính giữa. Phần trong của tấm hậu môn cũng thấy 1 gờ ngang. Mặt bên bụng của tấm hậu môn có một gờ khóa màu đen, dài. Mép cuối của tấm hậu môn tròn, không lõm.

Đôi chân thứ nhất không có thùy khớp háng. Đốt bàn chân có 4 gai ở mặt bụng và không có gai ở đỉnh. Đôi chân thứ hai có thùy khớp háng nhỏ, đốt bàn chân có 5-6 gai ở mặt bụng. Đôi chân thứ ba có 8 gai ở mặt bụng và 1 gai ở đỉnh đốt bàn chân. Các đôi chân sau có 8 gai ở mặt bụng và 1 gai ở đỉnh đốt bàn chân. Mặt bụng đốt trước đùi và đốt đùi có rìa sắc, mầu sẫm hơn so với màu vàng nâu hoặc xanh đen của chân. Tấm stigma của đốt chân thứ nhất dạng thùy, hình bậc thang.

Chân giao phối trước có 3 đốt có chiều dài gần bằng nhau, chiều rộng thuôn dần về phía đỉnh (hình $3 \mathrm{~A}-3 \mathrm{~B}$ ). Mặt trong đốt thứ hai có thêm phần phụ dạng mấu dài, tạo thành hình kẹp với đốt thứ ba (hình $3 \mathrm{~B}$ ).

Chân giao phối sau có 4 đốt. Đốt thứ hai có thùy dài, lớn dần về phía đỉnh. Đốt thứ ba ngắn, dài bằng đốt thứ hai, và có thêm một mấu nhỏ ở đỉnh về phía mặt trong (hình 3C-3D).

Nhận xét: Các đặc điểm của loài phù hợp với mô tả gốc của Verhoeff (1924). Địa điểm phân bố của loài được xác định ở khu vực tỉnh Ninh Bình. 


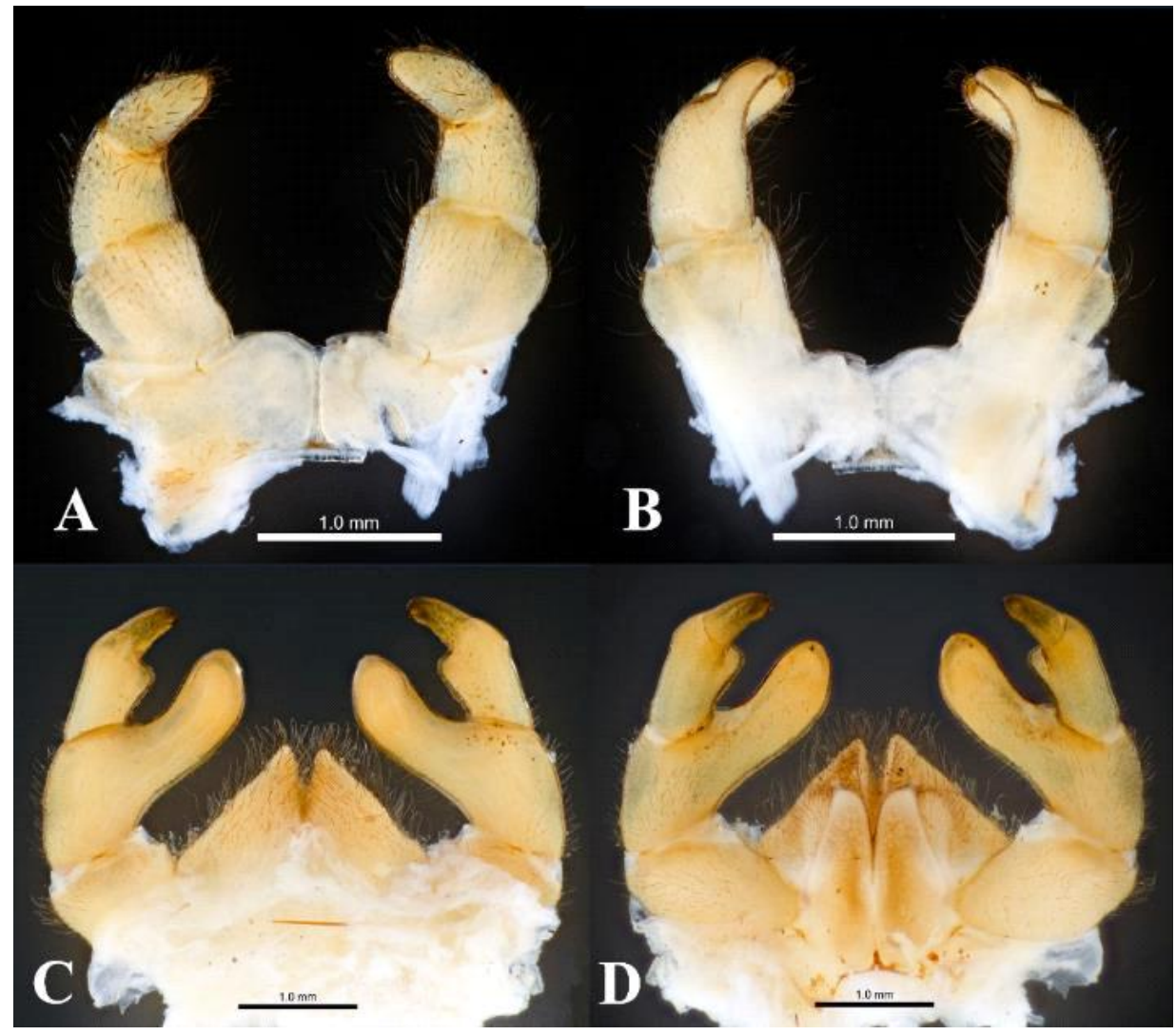

Hình 4. Sphaerobelum clavigerum Verhoeff, 1924, mẫu thu ở Cúc Phương: Chân giao phối trước, nhìn mặt trước $(\mathrm{A})$, nhìn mặt sau (B); Chân giao phối sau, nhìn mặt trước (C), nhìn mặt sau (D)

Sphaerobelum hirtusum Verhoeff, 1924 (hình 1B, 5-7)

Mẫu vât nghiên cứu: 1 cá thể đực, 3 cá thể cái (FMNH-SVE-22), 1 cá thể đực, 5 cá thể cái (FMNH-SVE-56), 1 cá thể cái (FMNH-SVE-201) Việt Nam, Vĩnh Phúc, Vườn Quốc gia Tam Đảo, N21²7'39,4”'E105'38'49,3”, 17-18/09/2016, coll. Petra Sierwald et al.; 2 cá thể non (FMNH-SVE103) Việt Nam, Vĩnh Phúc, Phúc Yên, Trạm đa dạng sinh học Mê Linh, N21 $23^{\prime} 66^{\prime}$ E105'42'43" 10-16/09/2016, coll. Petra Sierwald et al.; 1 cá thể đực, 1 cá thể cái (IEBR-Myr 602) Việt Nam, Vĩnh Phúc, Vườn Quốc gia Tam Đảo, rừng quanh thị trấn, 900-1.000 m, coll. Hoang Long.

\section{Mô tả:}

Có 13 đốt. Ở trạng thái cuốn tròn, chiều dài khoảng $20 \mathrm{~mm}$ (cá thể đực), $25 \mathrm{~mm}$ (cá thể cái), chiều rộng khoảng $15 \mathrm{~mm}$ (cá thể đực) and $18 \mathrm{~mm}$ (cá thể cái). Cơ thể có mầu đen, hoặc nâu đen. Chân có mầu vàng nâu.

Đầu có dạng hình thang. Lông nhỏ nhiều và dày đặc. Khu vực mắt tròn, có khoảng 60 mắt đơn. Cơ quan Tomosvary nằm giữa mắt và râu, nhưng tách biệt rõ ràng. Râu rất ngắn, đặc biệt các đốt $1-5$, đốt râu 6 rất lớn, dạng hình chùy, hoặc hình nắm tay; phần đỉnh râu có 43-44 nhú cảm giác.

Tấm cổ hình bán nguyệt, mầu đen sẫm, có rất nhiều tơ nhỏ; mép trước hơi cong về phía trước. Tấm khiên ngực có rất nhiều lông tơ nhỏ. Gờ sau tiêu giảm hoặc không rõ ràng; gờ trước rất rõ, lớn. Rãnh phân chia gờ trước và tấm khiên ngực sâu, dễ quan sát.

Tấm lưng có một gờ ngang nhỏ, chia tấm lưng thành 2 phần, phần trước có mầu nâu vàng, phần sau có mầu sẫm hơn. Trên tấm 
lưng có rất nhiều lông tơ nhỏ và các hạt nhỏ; lông nhỏ nằm rải rác và thưa thớt ở khu vực với mép trước của tấm lưng; và rất dày đặc ở các khu vực khác.

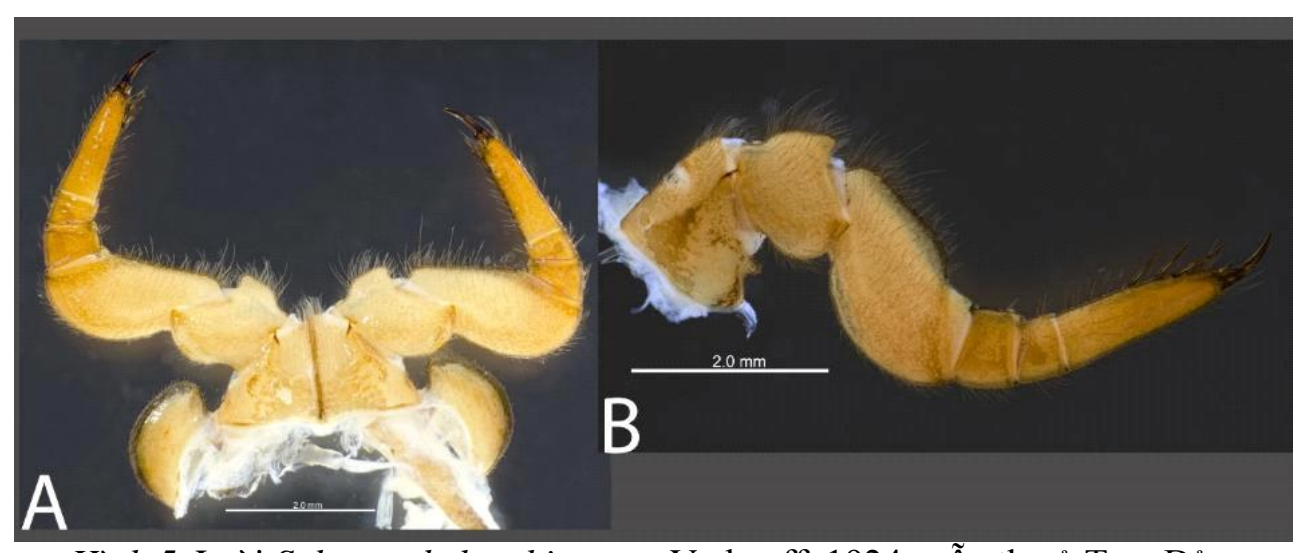

Hình 5. Loài Sphaearobelum hirsutum Verhoeff, 1924, mẫu thu ở Tam Đảo, chân thứ nhất (A), chân thứ hai (B)

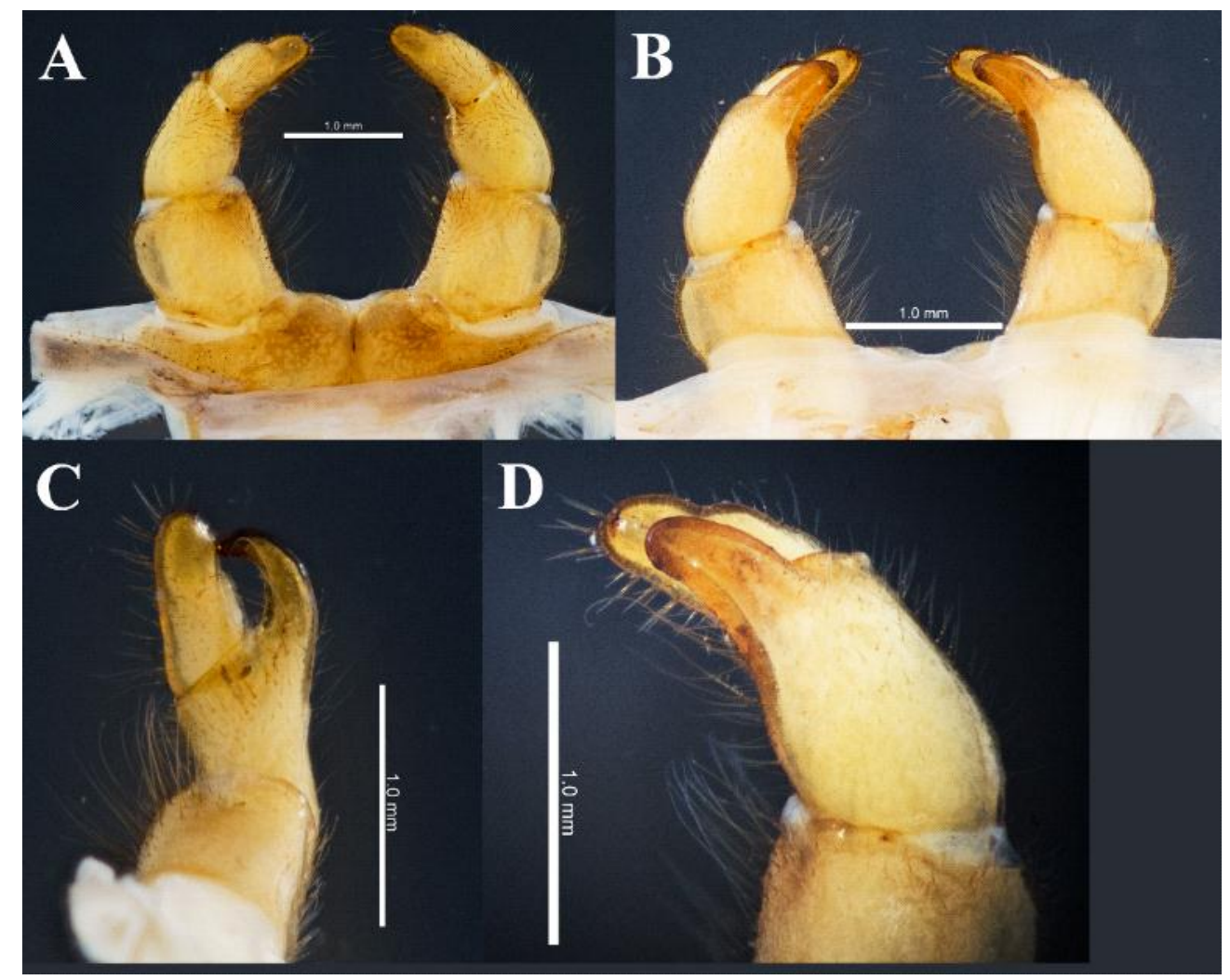

Hình 6. Cặp chân giao phối trước của loài Sphaerobelum hirsutum Verhoeff, 1924, mẫu thu ở Tam Đảo: Nhìn từ mặt trước $(\mathrm{A})$, nhìn từ mặt sau (B);

Chân trái, nhìn từ mặt trong $(\mathrm{C})$, nhìn từ mặt sau $(\mathrm{D})$

Tấm hậu môn có rất nhiều lông tơ nhỏ, hình tam giác tròn, nhưng chính giữa hơi lõm xuống đối với con đực. Phần trong của tấm hậu môn cũng có rất nhiều tơ nhỏ, và có 3 gờ 
ngang nhỏ. Mặt bên bụng của tấm hậu môn có một gờ khóa màu đen, dài.

Đôi chân thứ nhất không có thùy khớp háng. Đốt bàn chân có hai gai ở mặt bụng và không có gai ở đỉnh. Đôi chân thứ hai có thùy khớp háng nhỏ, đốt bàn chân có 4 gai ở mặt bụng. Đôi chân thứ ba có 6 gai ở mặt bụng và 1 gai ở đỉnh đốt bàn chân. Các đôi chân sau có 6-8 gai ở mặt bụng và 1 gai ở đỉnh đốt bàn chân. Mặt bụng đốt trước đùi và đốt đùi có rìa sắc, mầu sầm hơn so với màu vàng nâu của chân. Tấm stigma của đốt chân thứ nhất dạng thùy, hình lưỡi búa.
Chân giao phối trước có 3 đốt có chiều dài gần bằng nhau, chiều rộng thuôn dần về phía đỉnh (hình 6A-6D). Mặt trong đốt thứ hai có thêm phần phụ dạng mấu dài, tạo thành hình càng cua với đốt thứ ba (hình 6B-6D).

Chân giao phối sau có 4 đốt. Đốt thứ hai có thùy dài, lớn dần về phía đỉnh. Đốt thứ ba dài, hơi mở rộng về phía đỉnh (hình 6A-6B).

Nhận xét: Các đặc điểm của loài phù hợp với mô tả gốc của Verhoeff (1924). Địa điểm phân bố của loài được xác định ở khu vực tỉnh Vĩnh Phúc.

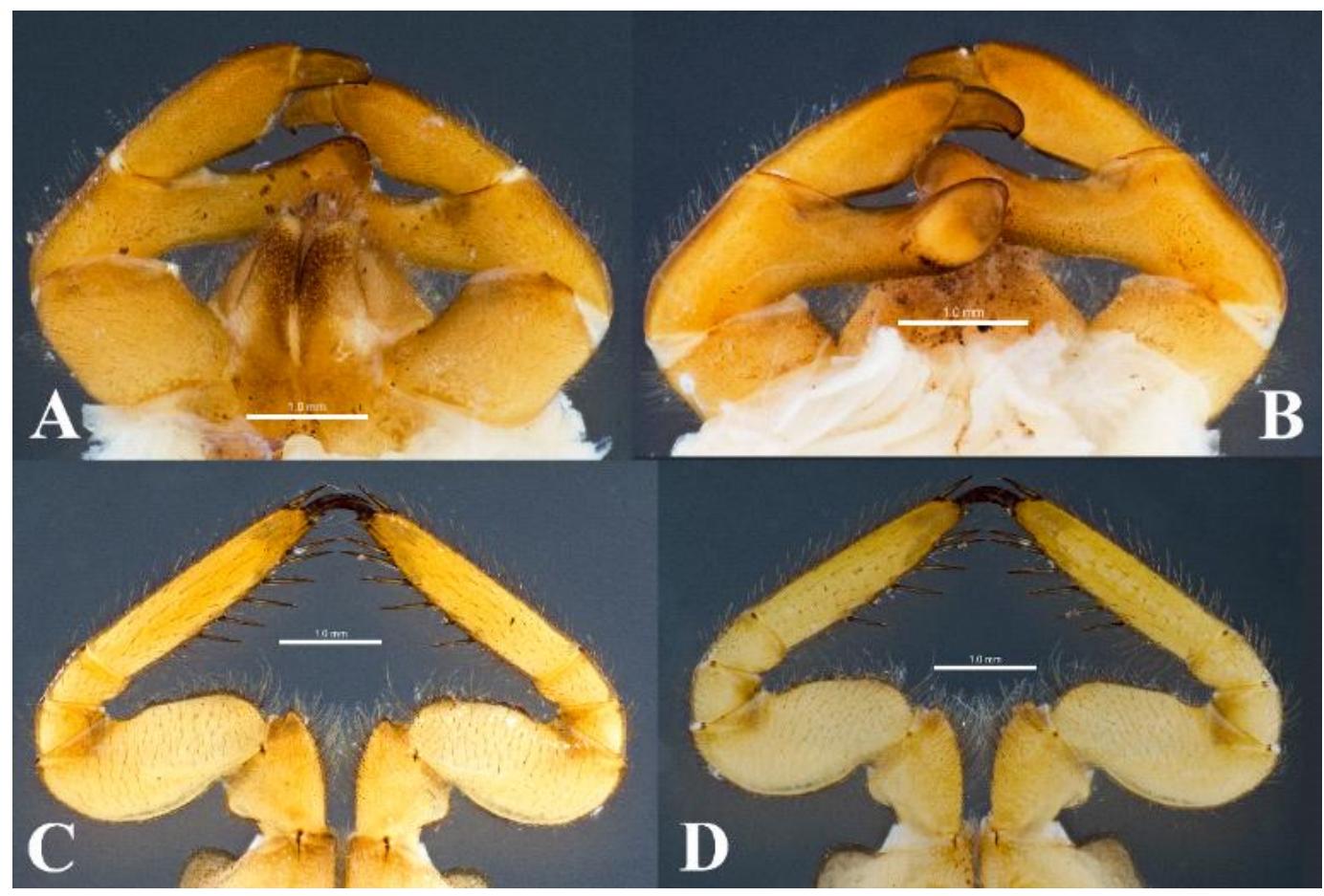

Hình 7. Cặp chân giao phối sau của loài Sphaerobelum hirsutum Verhoeff, 1924, mẫu thu ở Tam Đảo: Nhìn từ mặt sau (A), nhìn từ mặt trước (B); Cặp chân 20, nhìn từ mặt trước $(\mathrm{C})$, nhìn từ mặt sau $(\mathrm{B})$

\section{Khóa định loại đến giống của bộ Sâu đá lớn (Sphaeritheriida) ở Việt Nam}

1 Chân giao phối sau có 4 đốt. Phần phụ của đốt thứ hai, trơn nhẵn, không có các mấu lồi, hoặc

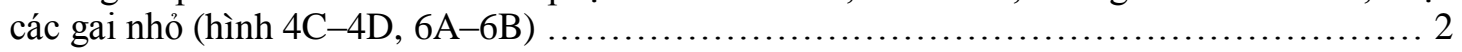

- Chân giao phối sau có 4 đốt. Phần phụ của đốt thứ hai, có các mấu lồi, hoặc các gai nhỏ ...... 3

2 Đốt bàn chân có nhiều gai ở đỉnh. Đốt thứ nhất của chân giao phối sau ngắn hơn so với các đốt 2-3. Zephronia

- Đốt bàn chân có 1 gai (hiếm khi có 2 gai) ở đỉnh (hình $3 \mathrm{C}-3 \mathrm{D}, 5 \mathrm{~A}-5 \mathrm{~B}$ ). Đốt thứ nhất của chân giao phối sau bằng với các đốt $2-3$ Sphaeropoeus 
3 Đốt thứ ba của chân giao phối trước cong nhiều về phía sau. Phần phụ đốt thứ hai lớn của chân giao phối sau thon, nhưng không lớn dần về phía đỉnh ...................... Prionobelum

- Đốt thứ ba của chân giao phối trước không cong nhiều về phía sau. Phần phụ đốt thứ hai lớn của chân giao phối sau lớn dần về phía đỉnh (hình 4C-4D, 7A-7B) Sphaerobelum

\section{KẾT LUẬN}

Hai loài sâu đá lớn, Sphaerobelum clavigerum Verhoeff, 1924 và S. hirsutum Verhoeff, 1924, được xác định địa điểm phân bố cụ thể ở Vườn Quốc gia Cúc Phương (Ninh Bình) và Vườn quốc gia Tam Đảo, và Vĩnh Yên (Vĩnh Phúc), tương ứng.

Lời cảm ơn: Các tác giả chân thành cảm ơn Vườn Quốc gia Cúc Phương, Tam Đảo và Trạm Đa dạng sinh học Mê Linh đã tạo điều kiện cho việc khảo sát thu mẫu tại địa phương. Công trình được thực hiện với sự hỗ trợ của đề tài cấp Viện Hàn lâm Khoa học và Công nghệ Việt Nam, mã số VAST04.10/19-20 cho Nguyễn Đức Anh và đề tài NSF DEB 1256150 cho Petra Sierwald.

\section{TÀI LIỆU THAM KHẢO}

Attems C., 1953. Myriopoden von Indochina. Expedition von Dr. C Dawydoff (19381939). Mémoires du Muséum National d'Histoire Naturelle \{N. S., Sér. A, Zool.\}, 5(3): 133-230.

Enghoff H., Golovatch S. I., Nguyen A. D., 2004. A review of the millipede fauna of Vietnam (Diplopoda). Arthropoda Selecta, 13(1-2): 29-43.

Hopkin S. P., Read, H. J., 1992. The biology of millipedes. Oxford University Press. Oxford.
Minelli A., 2015. The Myriapoda, Volume 2. Treatise on Zoology - Anatomy, Taxonomy, Biology. Brill Publisher. Leiden-Boston. $482 \mathrm{p}$.

Verhoeff K. W., 1924. Results of Dr. E. Mjöberg's Swedish scientific expeditions to Australia 1910-1913. Myriapoda: Diplopoda. Arkif för Zoologi, 16(5): 1-142.

Wesener T., 2016. The Giant Pill-Millipedes, order Sphaerotheriida - An annotated species catalogue with morphological atlas and list of apomorphies (Arthropoda: Diplopoda). Bonn Zoological Bulletin, Supplement: 1-104.

Wesener T., Raupach M. J., Sierwald P., 2010. The origins of the giant pillmillipedes from Madagascar (Diplopoda: Sphaerotheriida: Arthrosphaeridae). Molecular Phylogenetics and Evolution, 57(3): 1184-1193. https://doi.org/ 10.1016/j.ympev.2010.08.023.

Wongthamwanich N., Panha S., Sierwald P., Wesener T., Thirakhupt K., 2012. A new species of the giant pill-millipede genus Sphaerobelum Verhoeff, 1924 from northern Thailand, with an extensive description and molecular characters (Diplopoda: Sphaerotheriida: Zephroniidae). Zootaxa, 3220(1): 29-43. 